\title{
Assessment of Respiratory Muscle Fatigue in Patients with Neuromuscular Diseases: A Non-Invasive A pproach
}

\author{
Alfredo Chetta Marina Aiello \\ Department of Clinical Sciences, Section of Respiratory Diseases, University of Parma, Italy
}

Respiratory muscles, like limb muscles, experience fatigue, defined as a condition in which there is a loss in the muscle's capacity to exert force and/or velocity resulting from muscle activity under load, which is reversible by rest [1]. Respiratory muscle fatigue differs from respiratory muscle weakness, which is a condition in which the capacity of a muscle at rest to generate force is impaired [1].

Patients with neuromuscular diseases are predisposed to respiratory muscle fatigue.

Reduced maximal pressure capabilities and increased load, secondary to decreased lung and chest wall compliance, can facilitate the onset of fatigue [2]. Furthermore, in patients with neuromuscular diseases, because of respiratory weakness, fatigue may occur at a much lower load than in healthy subjects [2]. Respiratory muscle fatigue may play a role in the development of exertion breathlessness and ventilatory failure in patients affected by certain neuromuscular diseases, e.g. amyotrophic lateral sclerosis, muscular dystrophies and myopathies [3]. In these patients, measuring respiratory fatigue may be of clinical relevance.

During fatigue, muscles stiffen and sarcomere function may be expressed as both the velocity of shortening and relaxation of the muscle. Under fatiguing conditions, the relaxation rate of the diaphragm is slower than that of diaphragms without fatigue in normal subjects [4]. Ac- cordingly, slowing of the maximum relaxation rate(MRR) of inspiratory muscles during short and sharp sniffs is considered to be an index of inspiratory muscle fatigue [5]. Sniff MRR is commonly calculated from esophageal pressure traces; however, a non-invasive and reliable measure of inspiratory muscle MRR can be obtained by measuring sniff nasal pressure [6]. This non-invasive technique has been validated in healthy normal subjects [6] and in patients with chronic obstructive pulmonary disease [7].

A remarkable contribution to define the value of MRR by measuring sniff nasal pressure in patients with neuromuscular diseases has now been given by Garcì-Rìo et al. [8] in this issue of Respiration. In this prospective controlled study including 20 patients with diagnoses of neuromuscular diseases and 10 healthy subjects, the authors examined the relationship between MRR (of both sniff nasal and esophageal pressures) and the tension-time index of the diaphragm.

The authors found that patients with neuromuscular diseases had lower MRR values calculated from both esophageal and nasal pressure traces than control subjects. Furthermore, in these patients, the MRR assessed from sniff nasal pressure strongly predicted the corresponding MRR from esophageal pressure, and it was inversely related to the tension-time index of the diaphragm. Importantly, this study validates the sniff nasal MRR as

\section{KARGER \\ Fax +4161306 1234 E-Mailkarger@karger.ch} www.karger.com (c) 2006 S. Karger AG, Basel 0025-7931/06/0734-0412\$23.50/0

Accessible online at:

www.karger.com/res
Prof. Alfredo Chetta

Clinica Pneumologica, Azienda Ospedaliero-Università di Parma

Viale G. Rasori 10

IT-43100 Parma (Italy)

Tel. +390521 703 475, Fax +390521 292 615, E-Mail chetta@unipr.it 
a technique to assess - in a non-invasive manner - potential fatigue in patients with neuromuscular diseases. The measurement of inspiratory MRR by using sniff nasal pressure is simple and requires minimal cooperation from patients, even children, since it is based on a natural maneuver. This technique is limited only by lack of pa- tient cooperation or by a complete nasal obstruction. Measuring MRR without an esophageal balloon makes it a more acceptable test for patients with neuromuscular diseases and may facilitate further investigation of fatigue mechanisms and their role in exertion dyspnea and ventilatory failure.

\section{References}

1 NHLBI Workshop summary: Respiratory muscle fatigue. Report of the Respiratory Muscle Fatigue Workshop Group. Am Rev Respir Dis 1990;142:474-480.

2 Epstein SK: An overview of respiratory muscle function. Clin Chest Med 1994;15:619-639.

3 De Troyer A, Estenne M: The respiratory system in neuromuscular disorders; in Roussos Ch (ed): The Thorax. New York, Dekker, 1995, pp 1405-1461.
4 Esau SA, Bellemare F, Grassino A, Permutt S, Roussos C, Pardy RL: Changes in relaxation rate with diaphragmatic fatigue in humans. $\mathrm{J}$ Appl Physiol 1983;54:1353-1360.

5 Supinski GS, Fitting JW, Bellemare F: Assessment of respiratory muscle fatigue. Am J Respir Crit Care Med 2002; 166:571-579.

6 Kyroussis D, Mills G, Hamnegard CH, Wragg S, Road J, Green M, Moxham J: Inspiratory muscle relaxation rate assessed from sniff nasal pressure. Thorax 1994;49:1127-1133.
7 Kyroussis D, Johnson LC, Hamnegard CH, Polkey MI, Moxham J: Inspiratory muscle maximum relaxation rate measured from submaximal sniff nasal pressure in patients with severe COPD. Thorax 2002;57:254-257.

8 García-Río F, Mediano O, Pino JM, Lores V, Fernández I, Alvarez-Sala JL, Villamor J: Noninvasive measurement of the maximum relaxation rate of inspiratory muscles in patients with neuromuscular disorders. Respiration 2006;73:474-480. 